\title{
Ein unbekanntes Mariengebet im Archiv der Hansestadt Wismar
}

\author{
Anette Löffler
}

$\mathrm{B}$ ei den Katalogisierungsarbeiten zur abgelösten Makulatur im Archiv der Hansestadt Wismar trat im Bestand der Akten des Ratsarchivs ein loses Pergamentblatt zutage, das als Makulatur gedient hatte. ${ }^{.}$Das Blatt weist auf Vorder- und Rückseite Beschriftungen auf, die nicht in direktem Zusammenhang miteinander stehen, dazu später mehr.

Auf dem oberen Teil der Verso-Seite des Pergamentblattes findet sich ein Mariengebet im Umfang von neun Zeilen. Bei allen neun Zeilen fehlt jeweils der Zeilenbeginn, zu ergänzen wären aber nur sehr wenige Worte, maximal 2-3. ${ }^{2}$ Das Mariengebet ist einspaltig geschrieben. Die restliche Verso-Seite ist bis auf eine Notiz des 20. Jahrhunderts (s.u.) leer. Die Außenmaße des Blattes betragen $245 \times 155 \mathrm{~mm}$, der Schriftraum des Gebets $70 \times 130 \mathrm{~mm}$.

Bei der Schrift handelt es sich um eine sorgfältige, fast kalligraphische Bastarda. ${ }^{3}$ Manche Buchstaben werden wie in der Textualis aus einzelnen Teilen zusammengesetzt, andere in einem Schwung geschrieben. Die Sorgfalt des Schreibers ist auch daran erkennbar, dass lediglich in der siebten Zeile das Wort den interlinear eingefügt wurde. Die Buchstaben f und s sind unter die Zeile verlängert. Das a ist einbogig. Einige Buchstaben weisen noch Schlaufen auf. Schlaufen an den Oberlängen kommen bei $b, 1$, h und $d$ vor. Bei $d$ sind sie meist, bei $b$, h und 1 nur gelegentlich vorhanden. Auffällig sind auch die urkundenartig lang ausgezogenen Oberschäfte in der ersten Zeile. Damit unterscheidet sich diese Bastarda von den häufig völlig schlaufenlosen Schriften in niederdeutschen Handschriften der Devotio moderna. ${ }^{4}$ Die Charakteristika der Schrift weisen in die Mitte des 15. Jahrhunderts. Die Schreibsprache ist mittelniederdeutsch. ${ }^{5}$

Dass es sich bei der Verwendung des Blattes um eine Buchdeckelbeklebung gehandelt haben muss, ergibt sich aus der eigentlichen Recto-Seite. Dort befindet sich ein sehr stark beschädigter lateinischer Urkundentext des I4./I5. Jahrhunderts, welcher bis auf einen schmalen Streifen am oberen sowie einen breiteren Streifen am unteren Rand die gesamte Recto-Seite einnimmt. Diese Urkunde ist am rechten Rand abgeschnitten. Eine Rekonstruktion des Inhalts ist nicht möglich, die wenigen lesbaren Worte (opidani, Johannes, Hermannus, Henricus) und vor allem das mehrmalige Vorkommen des Wortes stipulatio lassen an eine Urkunde mit vertragsrechtlichem Inhalt denken, von denen sich eine große Anzahl im Wismarer Archiv befindet. Eine stipulatio ist ein Verbalvertrag des römischen Rechts, der eine bestimmte Leistung zum Gegenstand hatte. ${ }^{6}$ Sie fand in den Digesten in Buch 45 ihren Niederschlag. ${ }^{7}$

Auf dem oberen Rand der Recto-Seite ist außerdem ein dreizeiliger Leimabdruck zu erkennen. Bei diesem Text dürfte es sich um einen Ausschnitt aus einer Evangelienlesung handeln, die im I4. Jahrhundert niedergeschrieben wurde. Dieser ehemals zweispaltig angelegte Text, der zudem Rubrizierungen aufweist, scheint als Beklebung des inneren Deckels des ehemaligen Trägerbandes anzusprechen zu sein. Unser loses Blatt war entweder ebenfalls auf dieses Deckelblatt geklebt worden oder es diente als Vorsatz. Das Mariengebet wurde als letztes Element auf der leeren Rückseite dieses Fragments eingetragen.

Über die Funktion des Mariengebets auf dieser leeren Seite kann nur spekuliert werden. 
Mariengebete kommen einzeln oder als Teile von Gebetbüchern sehr häufig vor. ${ }^{8}$ Als Mutter Gottes nimmt Maria eine zentrale Stellung in Gebeten oder Fürbitten ein, die durch ihre Anrufung und dem gleichzeitigen Lobpreis Gottes gekennzeichnet sind. ${ }^{9}$ Im konkreten Fall könnte der Schreiber sich ganz allgemein der Unterstützung der Muttergottes versichert haben.

Das Blatt weist keine Kopertbeschriftung auf. Es lag lose in dem Aktenband des Ratsarchivs, dem es aber nicht als Kopert gedient haben konnte. Auf dem unteren Rand des Blattes befindet sich eine Bleistiftnotiz, Gebet und XXIII 8. Ia. Bei XXIII 8. Ia handelt es sich um die Signatur der entsprechenden Ratsakten, welche sich in diesem Konvolut befinden. Die Ratsakten mit den
Signaturen XXIII.8.I-XXIII.8.3 fehlen allerdings, was das lose Fragment erklärt: Sein Trägerband gehört zu den verschollenen Akten, von denen eben nur die Makulatur erhalten ist. Im alten Findbuch von 1914 heißt es, dass in den jetzt verschollenen Signaturen die „Nachricht von einigen Rathsbeschlüssen zur Ausmittelung des Salarii der ersten Lutherischen Prediger hierselbst“, die I53I und 1543 getroffen wurden, in der Abschrift des Diakons von St. Marien Dieterich Schröder (I74I) enthalten waren. Demnach handelte es sich um eine der ersten „Gehaltsabrechnungen“ aus nachreformatorischer Zeit, die dieses Fragment mit dem Mariengebet als Einbandmakulatur verwendet hatte.

\section{Transkription des Gebets:}

[...] systu aldermildeste Juncfrowe bauen allen Juncfrowen [...] du bust ene blogende rode rose vnde bauen alle crea= [...] eth deme clede der gotlyken leve Du bust ene snewitte [...] bylde der gantczen reynycheyt $\mathrm{Du}$ bust ene viole [...] akes Wente yn dyner oetmoeth heffstu hochliken vor [...] meth gnaden Vnde den hemmelen meth glorien Jck [...] dar lydent vnde den doeth dynes ghebenedygeden sones [...]llest vor my bydden dat he my gheue warafftighe leue [...] e oetmodicheyt wente (?) yn den doeth Amen.

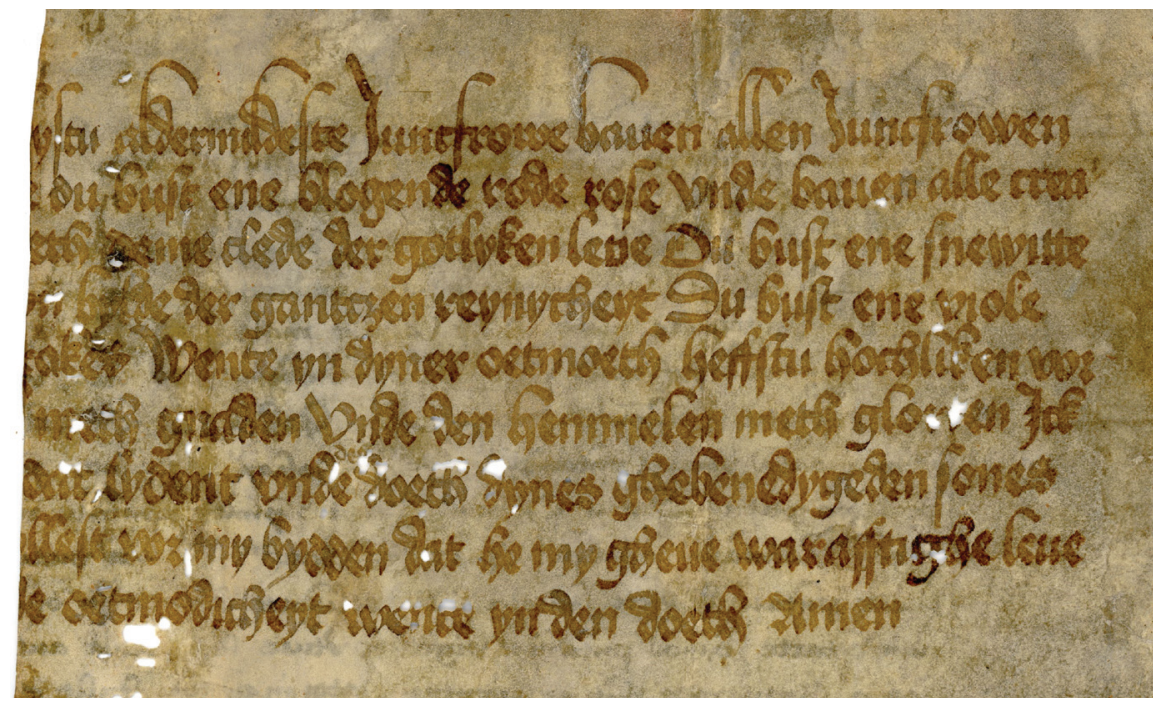

Abb. ı: Neunzeiliges Mariengebet auf der Verso-Seite des Fragments 


\section{Kontakt}

Anette Löffler

Pappelweg $2 \cdot 04683$ Threna

E-Mail: anette.loeffler@gmx.de

\section{Anmerkungen}

I Anette Löffler, Die mittelalterliche Makulatur in den Beständen des Archivs der Hansestadt Wismar, Wismar [202I], Nr. 264 .

2 Die I. Zeile beginnt sehr wahrscheinlich mit „Gegrüßt“.

3 Karin Schneider, Die datierten Handschriften der Bayerischen Staatsbibliothek München, Teil I, Stuttgart I994, S. XXII. Otto Mazal, Paläographie und Paläotypie. Zur Geschichte der Schrift im Zeitalter der Inkunabeln, Stuttgart 1984, S. I8-22. Elke von Boeselager, Schriftkunde, Hannover 2004, S. 38. Bernhard Bischoff, Paläographie des römischen Altertums und des abendländischen Mittelalters, Berlin ${ }^{42009}$, S. I9I-I93.

4 Wolfgang Ooeser, Beobachtungen zur Entstehung und Verbreitung schlaufenloser Bastarden. Eine Studie zur Geschichte der Buchschrift im ausgehenden Mittelalter, in: Archiv für Diplomatik 38 (1992), S. 235-343, hier S. 239-24I.

5 Karl Bischoff, Mittelniederdeutsch, in: Handbuch zur niederdeutschen Sprach- und Literaturwissenschaft, hg. von Gerhard Cordes, Dieter Möhn, Berlin 1983, S. 98-ı18.

6 Lothar von Seuffert, Materialien zur Deutung von stipulatio in mittelalterlichen Urkunden, in: Zeitschrift der Savigny-Stiftung für Rechtsgeschichte. Germ. Abt. 2 (I88I), S. II5-I23. Johannes Platschek, Pecunia constituta und stipulatio. Grenzen des Rechtsschutzes für formlose Geschäfte im römischen Recht, in: The letter. Law, State, Society and the Epistolary Format in the Ancient World Proceedings of a Colloquium, held at the American Academy in Rome 28-30.9.2008, ed. by Uri Yiftach-Firanko, Wiesbaden 2013, S. 239-249.

7 Paul Krüger, Theodor Mommsen (Ed.), Corpus iuris civilis, Bd. I: Digesten, Berlin I898, Digesta 45·3, S. 736-738.

8 Hanne Grießmann, Die Bibliothek im Buch - Mittelniederdeutsche Mariengebete aus den Augustiner-Chorfrauenstiften Heiningen bei Wolfenbüttel und Marienberg vor Helmstedt [Dissertationsprojekt Universität Osnabrück]. Für ihre Auskünfte danke ich Hanne Grießmann ganz herzlich.

9 Thomas Lentes, Gebetbuch und Gebärde. Religiöses Ausdrucksverhalten in Gebetbüchern aus dem Dominikanerinnen-Kloster St. Nikolaus in undis zu Straßburg (I350-1550), Münster 1996. Ruth Wiederkehr, Das Hermetschwiler Gebetbuch. Studien zu deutschsprachiger Gebetbuchliteratur der Nord- und Zentralschweiz im Spätmittelalter, Berlin/Boston 2013, bes. S. 137-139. 